\section{Epidemiology of microscopic colitis}

We read the interesting paper by Pardi et al on the epidemiology of microscopic colitis in Olmsted County, Minnesota, USA (Gut 2007; 56: 504-8). They concluded that the incidence of microscopic colitis increased significantly over time, and by the end of the study, the incidence and prevalence were significantly higher than reported previously. In fact, compared with other epidemiological studies, in the last years of the study period they describe the highest incidence figures of microscopic colitis ever reported.

However, is difficult to compare the crude incidence rates of several studies if we do not know the age structure of the population pyramid of each geographical area. As microscopic colitis is associated with older age, a higher incidence will be expected among aging populations. A solution for this is to report the standardised incidence rates; however, they are not reported in most of the published epidemiological studies. Another possibility is to describe the population pyramid of each geographical area. We think that the paper of Pardi et al would have been more understandable if they had described the population pyramid of Olmsted County. In our epidemiological study on the incidence of microscopic colitis in Terrassa, Spain, ${ }^{1}$ we reported the population pyramid. Thus, Pardi et al should assess if there are any differences in the age structure and sex structure of the population pyramids between Olmsted County and Terrassa. In this sense, if population pyramids were similar, they could conclude that there is a true difference in the incidence of microscopic colitis.

Fernando Fernández-Bañares, Maria Esteve, Josep Maria Viver

Department of Gastroenterology, Hospital Universitari Mutua Terrassa, Terrassa (Barcelona), Spain

Correspondence to: Dr F Fernández-Bañares,

Department of Gastroenterology, Hospital Universitari

Mutua Terrassa, Plaça Dr Robert 5, 08221 Terrassa (Barcelona), Spain; digestiu@mutuaterrassa.es

Competing interests: None.

\section{References}

1 Fernández-Bañares $F$, Salas $A$, Forné $M$, et al. Incidence of collagenous and lymphocytic colitis: a five-year population based study. Am J Gastroenterol 1999;94:418-23.

\section{Authors' response}

As Fernández-Banñares et al point out, it is difficult to compare crude incidence or prevalence rates across populations with different demographic structures. They suggest that we report our population pyramid to aid in interpreting the difference in microscopic colitis incidence observed in Minnesota compared with Spain. However, this would not be appropriate as there is no simple way to integrate the population structure with the various age- and sex-specific incidence rates and arrive at any kind of coherent conclusion. Instead, as they suggest, one should standardise the local incidence rates to an external reference population, which we, in fact, did in our paper. ${ }^{1}$ As we standardised our rates to the 2000 US white population, it would be the demographic "pyramid" to consider. Standardising their age- and sex-specific incidence rates to this same reference population to enable a direct comparison would be even better. Unfortunately, the age- and sex-specific incidence rates with which to accomplish this comparison are not reported in their paper.

The remaining alternative is to carry out an indirect standardisation, whereby we apply our own age- and sex-specific incidence rates to their population structure. Thus, if the ageand sex-specific incidence rates for microscopic colitis in Olmsted County, Minnesota, USA, in 1985-2001 ${ }^{1}$ are applied to the comparable ageand sex-specific denominator populations in the Hospital Mútua de Terrassa health distric of Terrassa, Spain in 1993-7, then one would expect to see 73 cases of microscopic colitis instead of the 60 cases that were actually observed. Thus, the Olmsted County rates are still higher even after accounting for any demographic differences between the two populations.

Therefore, explanations other than differences in the underlying age structure in our respective populations must be considered One possible explanation, as discussed in our paper, is different exposure rates in the two populations to certain environmental factors, such as medications, associated with microscopic colitis. ${ }^{2}$ Higher incidence rates could also be expected if a higher percentage of our population underwent sigmoidoscopy or colonoscopy with mucosal biopsies for the evaluation of diarrhoea-that is, differential application of the diagnostic test.

Darrell S Pardi, Edward V Loftus Jr, L Joseph Melton III, Alan R Zinsmeister Mayo Clinic College of Medicine, Rochester, Minnesota

Correspondence to: Dr D S Pardi, 200 First Street SW Rochester, MN 55905, USA; pardi.darrell@mayo.edu Competing interests: None.

\section{References}

1 Pardi DS, Loftus EV, Smyrk TC, et al. The epidemiology of microscopic colitis: a populationbased study in Olmsted County, Minnesota. Gut 2007;56:504-8

2 Beaugerie L, Pardi DS. Drug-induced microscopic colitis: a proposal for a scoring system and review of the literature. Aliment Pharmacol Ther 2005;22:277-84.

\section{Non-endoscopic immunocytological screening test for Barrett's oesophagus}

Surveillance strategies or chemoprevention of clinically diagnosed Barrett's oesophagus are unlikely to alter population mortality from oesophageal adenocarcinoma since it is estimated that only $5 \%$ patients with Barrett's oesophagus are diagnosed, despite the increasing use of endoscopy. ${ }^{1}$ Endoscopic screening for Barrett's oesophagus in white men aged over 50 years with chronic heartburn has therefore been advocated in the US. However, the prohibitive cost of endoscopy and the pathological expertise required make this screening programme problematic.

The aim of this study was to develop a screening test that did not rely on endoscopy and would be applicable to primary care. A non-endoscopic cytological test, which has been successfully used for the diagnosis of oesophageal squamous carcinomas in high-risk areas, was adapted by combining it with immunocytology. The device (bought from
Nanru Technologies, Bellville, South Africa) consists of a sponge contained within a gelatine capsule that dissolves in the stomach within 5 min (fig 1A,B). ${ }^{3}$ Liquid-based cytology was used to create a cell monolayer and the slides created were stained for minichromosome maintenance protein $2(\mathrm{Mcm} 2) . \mathrm{Mcm} 2$ is a proliferation marker that is abnormally expressed at the luminal surface in Barrett's oesophagus, with expression indices that correlate with the degree of dysplasia. ${ }^{4}$

Following approval from the Cambridge Local Research Committee, 43 patients with known Barrett's oesophagus (defined by endoscopy and a diagnosis of intestinal metaplasia) and 54 healthy volunteers were recruited (table 1). Diagnostic endoscopy was voluntary for healthy subjects, and, unfortunately, almost all (95\%) refused. The participants rated the acceptability of the capsule sponge as $4.0(2.0-9.0)$ using a linear scale of 0 (wors imaginable experience) to 10 (very enjoyable experience), where 5 was neither pleasant nor unpleasant. Of the patients with Barrett's oesophagus, $80 \%$ stated that they would choose the capsule sponge in preference to endoscopic surveillance. There were no complications, and 91 of $96(94.8 \%)$ samples were adequate for analysis. The squamous (red arrow) and columnar cells (black arrow) were easily distinguishable (fig $\mathrm{lC}, \mathrm{D}$ ) and goodquality immunostaining for $\mathrm{Mcm} 2$ was obtained (fig 1D).

A total of 27 of $40(67.5 \%)$ specimens of Barrett's oesophagus were positive compared with 17 of $52(32.6 \%)$ specimens from healthy volunteers, giving a sensitivity and specificity of $67.5 \%$ and $67.3 \%$, respectively. However, patients with Barrett's oesophagus with a positive test had a statistically longer segment than those with a negative test $(\mathrm{p}=0.01)$; therefore, if only patients with Barrett's oesophagus with a segment longer than $3 \mathrm{~cm}$ are considered as true Barrett's oesophagus, the sensitivity and specificity become $76.0 \%$ and $62.7 \%$, respectively. Since most volunteers did not undergo endoscopy, it was impossible to ascertain if they had Barrett's oesophagus. Heartburn is the primary risk factor for the presence of Barrett's oesophagus, and since nine $(53 \%) \mathrm{Mcm} 2$ positive controls were patients with a history of heartburn vs three ( $8 \%$ ) for the $\mathrm{Mcm} 2$ negative patients, there is a possibility that patients with heartburn might have Barrett's oesophagus. To correct for this possible bias, a post hoc analysis excluding all patients with heartburn was performed and the percentage of controls with a positive test result decreased from $37.5 \%$ to $20 \%$. In this subgroup analysis, the sensitivity and specificity were $67.5 \%$ and $80 \%$ for all patients, and $54.3 \%$ and $86.7 \%$, respectively, for patients with Barrett's oesophagus with a segment longer than $3 \mathrm{~cm}$.

In summary, the capsule sponge is acceptable to patients and applicable to primary care, thus bypassing the need for screening endoscopy. The immunostained monolayer specimen is amenable to automated microscopy processing. However, further refinements in technique to increase the sensitivity and specificity of this test are necessary before population-based studies can be performed, especially since the quoted specificity applies to a population with a $44 \%$ incidence of Barrett's oesophagus, and will be much lower if used in the general population. Overall, this proof-ofprinciple study suggests that a non-endoscopic 


\section{GUT Epidemiology of microscopic colitis}

Fernando Fernández-Bañares, Maria Esteve and Josep Maria Viver

Gut 2007 56: 1033

doi: 10.1136/gut.2007.123133

Updated information and services can be found at:

http://gut.bmj.com/content/56/7/1033.1.full.html

These include:

References This article cites 3 articles, 1 of which can be accessed free at: http://gut.bmj.com/content/56/7/1033.1.full.html\#ref-list-1

Email alerting Receive free email alerts when new articles cite this article. Sign up in the service box at the top right corner of the online article.

Notes

To request permissions go to:

http://group.bmj.com/group/rights-licensing/permissions

To order reprints go to:

http://journals.bmj.com/cgi/reprintform

To subscribe to BMJ go to:

http://group.bmj.com/subscribe/ 